\title{
Sonographic Evaluation of Obstructive Jaundice
}

\author{
Moawia Gameraddin ${ }^{1,2}{ }^{*}$, Suzan 0 Omer $^{2}$, Suliman Salih ${ }^{1,3}$, Suha A. Elsayed², \\ Abdalmonem Alshaikh ${ }^{1}$ \\ ${ }^{1}$ Department of Diagnostic Radiologic Technology, Faculty of Applied Medical Sciences, Al-Madinah \\ Al-Munawwarah, Saudi Arabia \\ ${ }^{2}$ Faculty of Radiological Sciences and Medical Imaging, Alzaiem Alazhari University, Khartoum, Sudan \\ ${ }^{3}$ National Cancer Institute, University of Gezira, Wad Medani, Sudan \\ Email: ${ }^{*}$ m.bushra@yahoo.com
}

Received 2 March 2015; accepted 17 March 2015; published 19 March 2015

Copyright (C) 2015 by authors and Scientific Research Publishing Inc.

This work is licensed under the Creative Commons Attribution International License (CC BY).

http://creativecommons.org/licenses/by/4.0/

(c) (i) Open Access

\begin{abstract}
Purpose: This study was done to assess the role of ultrasound in diagnosis of obstructive jaundice and to identify the most common causes and symptoms. Materials and methods: The study took place in different Khartoum clinical centers and hospitals in the period between Jan 2014 and July 2014. A total of 150 patients with obstructive jaundice were examined using ultrasound machine, 3.5 - 7 MHz probe. Results: The study revealed that 65.33 of the study population with obstructive jaundice were female and $34.67 \%$ was male. The most common affected groups were 46 - 65 years old and 25 - 45 years old. The common causes of obstructive jaundice were biliary stones (61.33\%) which were common in females and abdominal masses (32.67\%) which were common in females, too. Nausea, yellowish discoloration and abdominal pain were the most common symptoms (98\%, 97.33\% and $96.67 \%$ respectively). The causes of obstructive jaundice showed significant difference between males and females $(P$-value $=0.002)$. Conclusion: Ultrasound was superior diagnostic tool in detecting and assessing biliary system obstruction, because it was easy, available, accurate and noninvasive. The ageing and gender were considered as risk factors of obstructive jaundice.
\end{abstract}

\section{Keywords}

Sonography, Evaluation, Obstructive, Jaundice

\section{Introduction}

Obstructive jaundice is a particular type of jaundice and occurs when the essential flow of bile to the intestine is

"Corresponding author. 
blocked and remains in the bloodstream. This might be due to blocked bile ducts caused by gallstones, or tumors of the bile duct which can block the area where the bile duct meets the duodenum. These may be cancerous. Pancreatic cancer can also be a cause of blockages as it often occurs near to the ampulla of Vater which joins the pancreas gland to the duodenum. Other conditions that can cause obstructive jaundice include those that cause pressure on the bile duct such as swelling of lymph glands, scar tissue (from previous infections or surgery), or a cyst, possibly of the pancreas [1]. The majority of patients with suspected jaundice always present with yellowish skin, conjunctiva of eyes and mucous membrane. It is caused by an increase in the level of circulating bilirubin and becomes obvious clinically when level exceed $50 \mathrm{mmol} / \mathrm{l}$. Jaundice may result from excessive destruction of red cells (hemolytic jaundice), failure to remove bilirubin from the blood stream (hepatocellular jaundice), or obstruction to the flow of bile from the liver (cholestatic or obstructive jaundice). In literature, the causes of jaundice are classified into prehapatic, hepatic (intrinsic) and post hepatic (extrinsic). The intrinsic lesions include common bile duct (CBD) stone, cholangiocarcinoma and inflammatory occlusion due to wall thickening in patients with cholangitis [2], and the extrinsic lesions include pancreatic masses such as carcinoma of the head of pancreas, pancreatitis, pancreatic pseudocyst, periductaladenopathy and hepatic masses.

Obstructive jaundice is often referred to as surgical jaundice because operating will relieve the obstruction and permit the free flow of bile [3]. Ultrasound examination plays a great role in demonstrating the etiology of obstructive jaundice. Routine abdominal ultrasonography shows the size of the bile ducts, which may define the level of the obstruction and identify the cause, and gives other information related to the disease (e.g., hepatic metastases, gallstones, hepatic parenchymal change). It also identifies bile duct obstruction accurately though results are largely operator dependent and it readily demonstrates both benign and malignant causes of obstruction as well as any associated conditions and complications. Being relatively cheap, readily available and noninvasive, it is usually the preferred initial investigation [4]-[7]. So, it can very quickly demonstrate the result of an obstructing gall stones which are characterized by echogenic mobile structure with posterior acoustic shadowing.

The purpose of this work is to study the sonographic features of obstructive jaundice and to identify the most common causes and symptoms of the disease.

\section{Materials and Methods}

\subsection{Study Population}

This is a descriptive cross sectional study conducted in Khartoum State from January 2014 to July 2014. The study population was composed of 150 cases that had been selected randomly with clinical features of jaundice. They were 98 females and 52 males, ages ranged from 25 to 86 years old. The patients were categorized into four age groups to study whether the age could be regarded as risk factor of obstructive jaundice and to identify the incidence of biliary stones and masses among the age groups. These patients were diagnosed clinically with obstructive jaundice. All patients were given informed consent. They were referred to ultrasound to detect and assess the causes of obstructive jaundice.

\subsection{Ultrasound Scanning Procedure}

The ultrasound examinations were performed by experience sonographers and sonologists. All patients were scanned by more than one sonologist with the same ultrasound machine using the same international guidelines and protocols for performing the ultrasound investigation. The liver, pancreas and hepatic ducts were scanned with ultrasound using 3.5 to $5 \mathrm{MHz}$ probe. Ultrasonic jell was used to ensure good contact between the transducer and the skin and allow total transmission of the sound beam. The sonographic display parameters such as overall gain, focusing and depth gain compensation had been adjusted to enhance visibility of the images.

The liver was scanned in transverse and longitudinal sections. The normal liver showed homogenous echo texture, thus focal masses could easily be detected. To find the common hepatic duct, the sonologist must identify the straight segment of the right portal vein. By using a right subcostal or lower intercostal window with the patient in the supine, the gall bladder and liver could be well demonstrated. The common hepatic duct is identified anterior to the right portal vein when the transducer is rotated slightly.

The pancreas was scanned with the probe placed at the epigastric region using longitudinal and transverse sections with the patient in the supine position. The patient is ordered to drink water to facilitate visualization of 
the pancreas. Malignant tumors of pancreas are always hypoechoic heterogeneous irregular masses and mainly involved the pancreatic head. The major limitations of this study were due to the ignorance of patients towards ultrasound investigation, they assumed that ultrasound had hazards as the same as ionizing radiations.

\subsection{Statistical Analysis}

Data were analyzed and initially summarized as mean \pm SD in a form of comparison tables. Statistical analysis was performed using the standard Statistical Package for the Social Sciences (SPSS Inc., Chicago, IL, USA) version 16 for windows. Descriptive statistics were used to describe variables; percent for qualitative variables. Spearman Correlation and Qi-square tests were used to find relationship between causes of obstructive jaundice and age and gender variables. P-values $<0.05$ were considered to be significant.

\section{Results}

A total of 150 patients were seen during the study period with obstructive jaundice. They had been investigated with ultrasound using the abdomen imaging protocol. The study population composed of 52 males and 98 female as shown in Table 1. Their ages ranged from 25 to 85 years old. Table 2 showed distribution of age groups of the study population. Most of jaundiced patients were emphasized at the age group of 46 - 65 years old. Table 3 showed the relationship between ultrasound findings (causes) and age. There was association between causes and age (P-value $=0.002)$; this indicated that prevalence of obstructive jaundice increased as age advanced. The frequency of symptoms is shown in Table 4; nausea, yellow discoloration and abdominal pain are

Table 1. Frequency distribution of gender.

\begin{tabular}{ccc}
\hline Gender & Frequency & Percent \% \\
\hline Males & 52 & 34.67 \\
Females & 98 & 65.33 \\
Total & 150 & 100 \\
\hline
\end{tabular}

Table 2. Frequency distribution of age groups of the study population.

\begin{tabular}{ccc}
\hline Age groups (years old) & Frequency & Percent \% \\
\hline $25-45$ & 54 & 36.00 \\
$46-65$ & 60 & 40.00 \\
$66-85$ & 24 & 16.00 \\
$\geq 86$ & 12 & 8.00 \\
Total & 150 & 100 \\
\hline
\end{tabular}

Table 3. Causes of obstructive jaundice among study population and relationship with age.

\begin{tabular}{|c|c|c|c|c|c|c|c|c|}
\hline \multirow{3}{*}{$\begin{array}{c}\text { Ultrasound findings } \\
\text { Age groups }\end{array}$} & \multicolumn{8}{|c|}{ Age groups (years old) } \\
\hline & \multicolumn{2}{|c|}{$25-45$} & \multicolumn{2}{|c|}{$46-65$} & \multicolumn{2}{|c|}{$66-85$} & \multicolumn{2}{|c|}{$>86$} \\
\hline & $\mathrm{N}$ & $\%$ & $\mathrm{~N}$ & $\%$ & $\mathrm{~N}$ & $\%$ & $\mathrm{~N}$ & $\%$ \\
\hline Biliary stones & 42 & 77.8 & 38 & 63.3 & 5 & 20.8 & 7 & 58.3 \\
\hline Abdominal masses & 9 & 16.6 & 22 & 36.7 & 16 & 66.7 & 2 & 16.7 \\
\hline Others & 3 & 5.6 & 0 & 0 & 3 & 12.5 & 3 & 25 \\
\hline Total & 54 & 100 & 60 & 100 & 24 & 100 & 12 & 100 \\
\hline P-value & \multicolumn{8}{|c|}{0.002} \\
\hline
\end{tabular}


the highest values (98\%, $97.33 \%$ and $96.67 \%$ respectively). Table 5 shows the causes of obstructive jaundice at males and females. The biliary stones and abdominal masses were the most common causes of obstructive jaundice. There was a significant relationship between the sonographic findings and gender. It was observed that the causes of obstructive jaundice showed significant difference between males and females (P-value $=0.003$ ). Figure 1 and Figure 2 were sonograms had been taken from the study results showing dilatation of intrahepatic ducts and gall stones respectively.

Table 4. Frequency distribution of symptoms of obstructive jaundice among the study population.

\begin{tabular}{ccc}
\hline Symptoms & Frequency & Percent \% \\
\hline Fever & 84 & 56.00 \\
Nausea/vomiting & 147 & 98.00 \\
Yellow discoloration & 146 & 97.33 \\
Abdominal pain/RUQ pain & 145 & 96.67 \\
Abdominal mass & 3 & 2.00 \\
Abdominal distention & 30 & 20.00 \\
Weight loss & 35 & 23.33 \\
\hline
\end{tabular}

Table 5. Relationship between sonographic findings (causes) and gender.

\begin{tabular}{|c|c|c|c|c|}
\hline \multirow{3}{*}{ Findings } & \multicolumn{4}{|c|}{ Gender } \\
\hline & \multicolumn{2}{|c|}{ Male } & \multicolumn{2}{|c|}{ Female } \\
\hline & $\mathrm{N}$ & $\%$ & $\mathrm{~N}$ & $\%$ \\
\hline Biliary stones & 41 & 27.33 & 51 & 3461.33 \\
\hline Abdominal masses & 8 & 5.33 & 41 & 27.3332 .67 \\
\hline Others & 3 & 2 & 6 & 46 \\
\hline Total & 52 & 34.67 & 98 & 65.33100 \\
\hline P-value & \multicolumn{4}{|c|}{0.002} \\
\hline
\end{tabular}

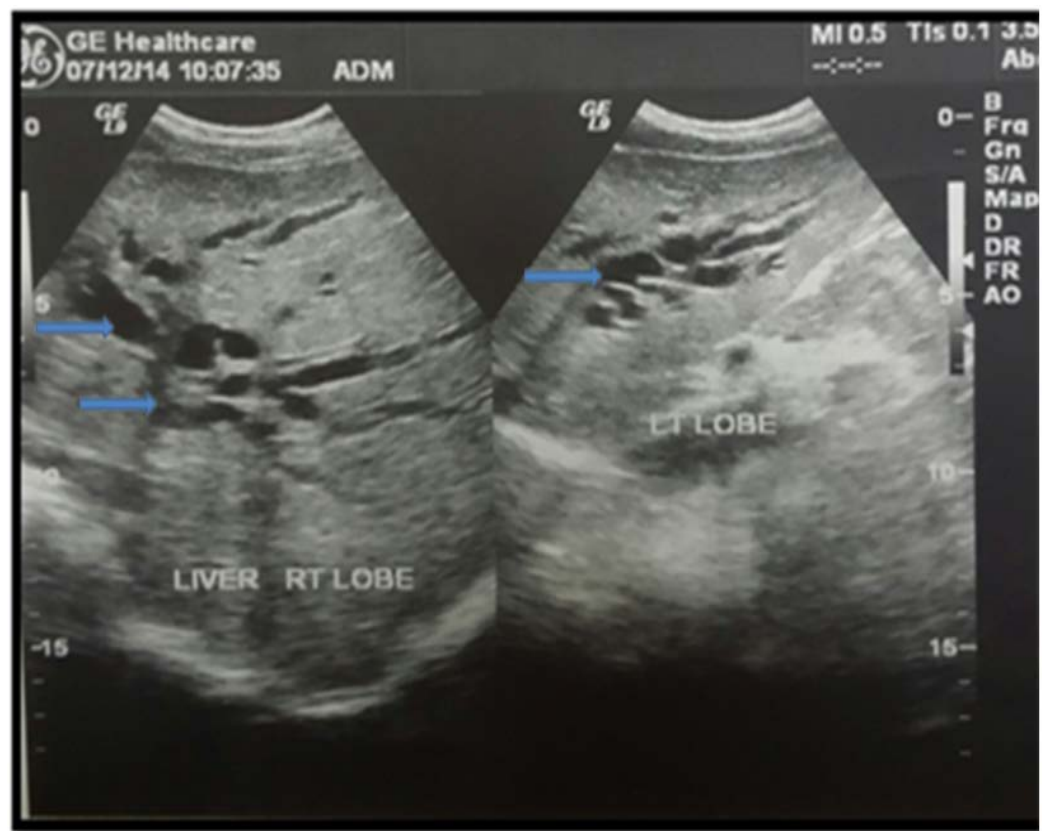

Figure 1. Sonogram of a 60-year-old male showing dilation of intrahepatic ducts. 


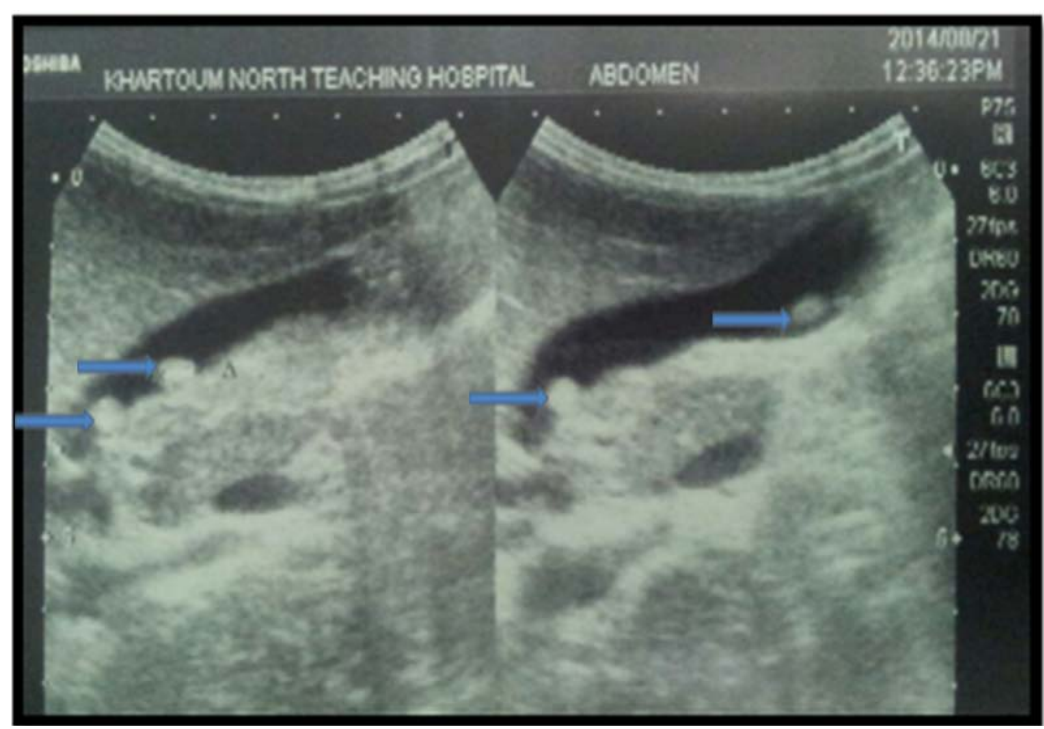

Figure 2. Sonogram of a 35-year-old female showing multiple gall stones.

\section{Discussion}

The major sonographic feature of obstructive jaundice is dilatation of intra and extra-hepatic biliary ducts which are visible at longitudinal and transverse scanning. In longitudinal section two anechoic tubes are seen side by side and in transverse section the dilated bile ducts and adjacent portal vein branch are seen as two adjacent anechoic circles [8]. In this study, it is observed that obstructive jaundice involves female more than male (65\% vs. 35\%) of our study sample. This result is consistent with a study conducted by Gameradin et al. [9] who reports that female is more frequent affected with obstructive jaundice than males (58\% vs. $42 \%)$. Another study confirms that the frequency of obstructive jaundice is higher among female population, and the most frequent causes of obstructive jaundice are gall stones (54.1\% of patients) [10].

The incidence of obstructive jaundice increases as age advances, this is attributed to deficiency of immunity, and thus the incidence of masses and stones are probably increased. In our study, it is noticed that prevalence of obstructive jaundice occurrs after age of 50 years old. The age group of 66 - 80 years old is the most affected group (64\%). This result is consistent with Gameradin et al. [9] who stated that the most affected groups were 45 - 75 and 75 - 95 years old respectively. Another study [11] reveals the range age between 60 - 70 years old is the most involved and this is also in agreement with our finding.

In this study, biliary stone (in bile duct or gall-bladder) is the first common cause of obstructive jaundice (61.3\%) as it obstructs flow of bile which is retained in liver tissue and causes yellow discoloration. The sonographic appearance of stone is characterized by its echogenicity, focal shape and produces sharp acoustic shadowing. A study done by Verna et al. [12] had studied the aetiological spectrum of obstructive jaundice; they reported that malignant obstructive was more common than benign (62.73\% vs. $47.27 \%)$, carcinoma of the head of pancreas was the commonest aetiology (33.63\%) followed by choledocholiathiasis (29\%). They concluded that carcinoma of head of pancreas and choledocholithiais were the commonest malignant and benign etiology respectively. In present study, gall stones are more common in females than males (61.33\% vs. $27.33 \%)$. The masses represent the common cause of obstructive jaundice. In this study, abdominal masses are the second cause (32.67\%) of obstructive jaundice. In this study, these masses are not differentiated as benign and malignant; this needs biopsy and histopathological analysis which have been taken after ultrasound investigation. This result agrees with a study done by Iqbal et al. [11] who reported that 32\% of the causes of obstructive jaundice were Ca-head of pancreas. In literature, tumours causing biliary channel obstruction are generally ampullary carcinomas, gall bladder carcinomas extending into the CBD, metastatic tumours (usually from the gastrointestinal tract or the breast), secondary lymphadenopathies at the portahepatis and cholangio carcinomas [12]. In our study, abdominal masses are observed in females more than males (27.33 vs. 5.33 respectively). In previous studies, the disease is more common in men than women [13] [14] though the difference in rates has narrowed over recent decades, probably reflecting earlier increases in female smoking. In the United States the risk for African 
Americans is over $50 \%$ greater than for whites, but the rates in Africa and East Asia are much lower than those in North America or Europe. The United States, Central and Eastern Europe, Argentina and Uruguay all have high rates [15].

The present study has identified the main symptoms of the obstructive jaundice. It is observed that vomiting, yellow discoloration and abdominal pain are the most common symptoms. In literature, the signs and symptoms of obstructive jaundice differ depending on the completeness of the blockage, and the disease course varies among individuals. Some people with obstructive jaundice may have no symptoms initially, but if the condition persists, they may have severe abdominal pain, fever, nausea, and vomiting. Complete blockage may also occur, posing a risk of infection leading to liver and gallbladder damage [16].

\section{Conclusion}

Ultrasound plays a great role in detecting and evaluating obstructive jaundice and it should be the first line of investigation. The main causes of obstructive jaundice are biliary stones and carcinoma of the head of pancreas respectively. Gender and age show significant difference with the causes of obstructive jaundice.

\section{References}

[1] http://www.liverandpancreas.co.uk/the-management-of-obstructive-jaundice.php

[2] Gardene, O.J., Bradbury, A.W. and Forsythe, J.L.R. (2002) Principle and Practice of Surgery. 4th Edition, Churchill Livingstone, Edinburgh, 278.

[3] Devin, M. (2005) Ultrasound of the Abdomen and Small Parts. The Burwin Institute of Diagnostic Medical Ultrasound, Winnipeg. http://www.burwin.com/html/courses/ardms/ardms-003-004-ultrasonography-abdomen-small-parts.html

[4] Martin, D.F. and Laasch, H.U. (2001) The Biliary Tract. In: Grainger, R.G., Allison, D., Adam, A. and Dixon, A.K., Eds., Grainger \& Allison's Diagnostic Radiology: A Textbook of Medical Imaging, 4th Edition, Churchill Livingstone, Harcourt Publishers Limited, London, 53-55.

[5] Geier, A., Gartung, C., Dietrich, C.G., Lammert, F., Wasmuth, H.E. and Matern, S. (2003) Diagnosis of Cholestatic Disorders. Medizinische Klinik (Munich), 98, 499-509. http://dx.doi.org/10.1007/s00063-003-1294-5

[6] Admassie, D., H/Yesus, A. and Denke, A. (2005) Validity of Ultrasonography in Diagnosing Obstructive Jaundice. East African Medical Journal, 82, 379-381.

[7] Sharma, M.P. and Ahuja, V. (1999) Aetiological Spectrum of Obstructive Jaundice and Diagnostic Ability of Ultrasonography: A Clinician’s Perspective. Tropical Gastroenterology, 20,167-169.

[8] Bisset, R. and Khan, A.N. (2002) Differential Diagnosis in Abdominal Ultrasound. W.B.Saunders, London, 135.

[9] Gameraddin, M., Abdalgaffar, R. and Yousef, M. (2013) The Role of Ultrasound in Diagnosis of Obstructive Jaundice Causes in Sudanese Population. IOSR Journal of Nursing and Health Science, 1, 25-28. http://www.iosrjournals.org/iosr-jnhs/papers/vol1-issue4/E0142528.pdf http://dx.doi.org/10.9790/1959-0142528

[10] Gracanin, A.G., Kujundzić, M., Petrovecki, M., Romić, Z. and Rahelić, D. (2013) Etiology and Epidemiology of Obstructive Jaundice in Continental Croatia. Collegium Antropologicum, 37, 131-133. http://www.ncbi.nlm.nih.gov/pubmed/23697262

[11] Iqbal, J., Khan, Z., Afridi, F.G., Alam, A.W.J., Alam, M., Zarin, M., et al. (2008) Causes of Obstructive Jaundice. Pakistan Journal of Surgery, 24, 12-14.

[12] Verma, S., Sahai, S., Gupta, P., Munshi, A. and Goyal, P. (2010) Obstructive Jaundice-Aetiological Spectrum, Clinical, Biochemical and Radiological Evaluation at a Tertiary Care Teaching Hospital. The Internet Journal of Tropical Medicine, 7. https://ispub.com/IJTM/7/2/13053\#

[13] Bonheur, J.L. and Ellis, P. (2001) Biliary Obstruction. Emedicine. http://www.emedicine.com/med/topic3426.htm

[14] Ryan, D.P., Hong, T.S. and Bardeesy, N. (2014) Pancreatic Adenocarcinoma. New England Journal of Medicine, 371, 1039-1049. http://dx.doi.org/10.1056/NEJMra1404198

[15] World Health Organization (2014) World Cancer Report, Chapter 5.7. WHO, Geneva.

[16] http://www.healthgrades.com/conditions/obstructive-jaundice 